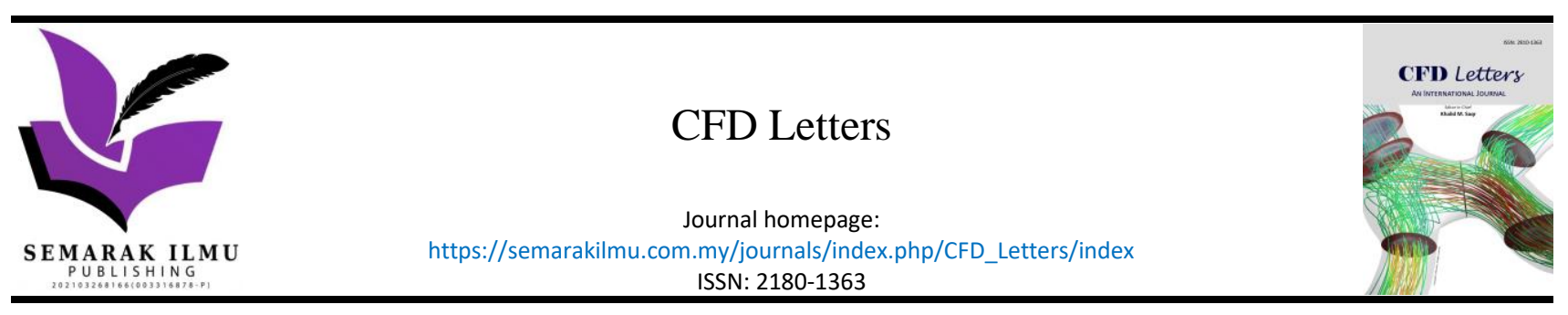

\title{
Comparison of 2D and 3D Modelling Applied to Single Phase Flow of Nanofluid through Corrugated Channels
}

\author{
Elhadi Kh. Abugnah ${ }^{1,}{ }^{*}$, Wan Saiful-Islam Wan Salim ${ }^{1}$, Abdulhafid M. Elfaghi $^{1}$, Zamani Ngali ${ }^{1}$ \\ 1 Faculty of Mechanical and Manufacturing Engineering, University Tun Hussein Onn Malaysia, 86400 Batu Pahat, Johor, Malaysia
}

\section{ARTICLE INFO ABSTRACT}

\section{Article history:}

Received 5 December 2021

Received in revised form 13 December 2021

Accepted 16 December 2021

Available online 9 January 2022

\section{Keywords:}

Nanofluid modelling; Numerical simulation; Heat transfer; pressure drop analysis

\begin{abstract}
Nanofluid flow through non-corrugated and corrugated channels is studied using a two-dimensional (2D) and three dimensions (3D) numerical simplification. Due to the high computational costs of a full 3D grid model, the 2D approach offer a more practical advantage. However, little information about its validity is available. The aim of this study is to explore to which extent 2D simulations can describe the flow within a 3D geometry, and to investigate how effective the commonly used 2D numerical simplification is in nanofluid flow through non-corrugated and corrugated channels. A case study has implemented with 2D and 3D mesh models to compare their results taking into consideration the analysis of heat transfer and pressure drop. A simulation has been carried out using Ansys fluent software to compare the results for different Reynolds Numbers ranges from 10000 to 30000 and different geometries noncorrugated, semicircle and rectangular channels. The results show that for noncorrugated channel there is a slight difference between 2D and 3D results for all Reynolds number ranges, while for both semicircle and rectangular corrugated channels, the difference becomes larger for high Reynold's Number.
\end{abstract}

\section{Introduction}

Industries are constantly pushing to improve thermal performance of heat transfer devices in recent years to increase efficiency, reduce cost, size and weight. In unmixed-flow devices with fluidcarrying channels or conduits, the corrugated heat transfer surface can be used instead of the flat surface. One of the most important advantages of using corrugated channels is that it reduces the thickness of the thermal boundary layer. As a result of the appearance of secondary flow regions in through of corrugated channel, the geometry of corrugated surface is considered an efficient way to upgrade the heat transfer in these devices, which leads to improved blending of the fluid medium and maximize the heat transfer exchange. Furthermore, using nanofluids can also enhance heat transfer. Numerous works investigates these systems numerically an experimentally, aiming to decide the best geometry and the proper nanofluid. Ajeel et al., [1] applied Computational Fluid Dynamics (CFD) simulations to analyze heat transfer and friction factor in a turbulent flow through

\footnotetext{
* Corresponding author.

E-mail address: abujnah661@gmail.com (Elhadi Kh. Abugnah)
} 
semi-circle corrugated channels with $\mathrm{Al}_{2} \mathrm{O}_{3}$-water nanofluid. The results were compared to those from non-corrugated channels. Results showed that the Nusselt number $(\mathrm{Nu})$ increased with the increase of Reynold's number $(R e)$ and volume fraction of the nanoparticles $(\phi)$. The Nu was found to rise as the diameter of the nanoparticles decreased. The maximum enhancement ratio of Nusselt number was 2.07 at Reynolds number 30,000 and 6 percent volume fraction.

Ajeel et al., [2] applied a 3D numerical simulation to compare the thermal performance of different corrugated channel geometries as well as non-corrugated channels in a turbulent flow of ZnO-water nanofluid under constant heat flux. They employed finite volume method with the SIMPLE pressure-velocity coupling technique to solve the mathematical model. They use several forms of corrugated channels, including trapezoidal, house-shaped, and semicircle channels, were tested using nanoparticles volume fractions and Reynolds number ranging from 0 to 0.08 and 10,000 to 30,000 , respectively. The work demonstrated the high impact of corrugation shapes on both heat transfer and pressure drop.

Over Reynolds number ranges of 10,000-30,000, Ajeel et al., [3] investigated numerically heat transfer and flow characteristics of the symmetry semicircle-corrugated channel with $\left(\mathrm{SiO}_{2}\right)$ water nanofluid. They looked at A 3D numerical simulation of nanoparticles volume fractions ranging from 0 to $8.0 \%$ were conducted. The work investigates how geometrical parameters like pitch to length ratio (pch/L) and height to width ratio (h/W) affected thermal and hydraulic properties. In comparison to the pitch to length ratio, the results revealed that the height to width ratio has a greater influence on heat transfer promotion.

For a long time, the computational power of 3D numerical simulations was limited, so 2D models were preferred for flow structure analysis. Rostamani et al., [4] simulated the turbulent flow of nanofluids with different nanoparticle volume fractions through a 2D duct under constant heat flux condition. Using the 2D models, several interesting results were obtained, as well as several innovative ideas. Because of the known limitations of the 2D approach, the validity of the models used is questioned. Krishnappa et al., [5] compared three numerical models depends on the assumption of one-dimensional flow, namely isothermal, adiabatic, and energy equation models, with a (CFD) model based on a 2D flow approach to analyze a two-stage pulse tube cryocooler. Various experimental parameters have been incorporated into the models to carry out the analysis. The pulse tube cryocooler's various losses are calculated separately and incorporated into the 1D models. For validation, the numerical results are compared to experimental results obtained for a two-stage pulse tube cryocooler. The heat transfer due to laminar flow of copper-water nano-fluid through a 2D channel with constant temperature walls is studied by Santra et al., [6]. They concluded that the rate of heat transfer increases as the flow Reynolds number and the solid volume fraction of the nano-fluid increase. Li et al., [7] simulated the forced convection heat transfer occurring in siliconbased microchannel heat sinks by using a simplified 3D conjugate heat transfer model (2D for the fluid flow and 3D for the heat transfer). Manca et al., [8] in a 2D channel, a numerical investigation of forced convection with nanofluids composed of water and $\mathrm{Al}_{2} \mathrm{O}_{3}$ nanoparticles is carried out. On the exterior walls, a uniform heat flux is applied. To model nanofluids, a single-phase approach is used, and the fluid properties are assumed to be constant with temperature. The particle size is set to $38 \mathrm{~nm}$, and nanoparticle volume fractions ranging from $0 \%$ to $4 \%$ are taken into account. The flow is turbulent, with Reynolds numbers ranging from 20,000 to 60,000. In addition, different arrangements of ribs and square and rectangular shapes are analyzed in terms of different dimensionless heights and pitches of elements. Temperature and velocity fields, as well as profiles of average Nusselt number, average heat transfer coefficients, and required pumping power, are presented. Heat transfer efficiency improved as particle volume concentration raised, but so did the amount of pumping power require. As the Reynolds number raised, heat transfer improved, but 
pumping power must also rise. Ahmed et al., [9] studied heat transfer and pressure drop numerically using 2D corrugated channels and a Cu-water nanofluid over low Reynolds number ranges of 1001000. The findings of this study showed that increasing the nanofluid volume fraction and Reynolds number had a similar effect on heat transfer when combined with a small increase in pressure drop. Al-Shamani et al., [10]. investigated the numerical study of heat transfer due to turbulent nanofluid flow through rib-groove channels, they used different types of nanofluids, different nanoparticle volume fractions, and different nanoparticle diameters, which were dispersed in base fluids (water) over a horizontal channel with different rib-groove shapes. The Trapezoidal with increasing height in the flow direction rib-trapezoidal groove has the best heat transfer rate and a high Nusselt number, according to the results. In comparison to other types of nanofluids, the $\mathrm{SiO}_{2}$ - nanofluid has the highest Nusselt number. The Nusselt number rises with increasing volume fraction and falls with increasing nanoparticle diameter. Using single-phase flow, Kriby et al., [11] studied the thermal and hydrodynamic behavior of a nanofluid flowing in turbulent conditions through the pipe. Analyses were performed on $\mathrm{Al}_{2} \mathrm{O}_{3}$ and Copper oxide nanoparticles to determine how they affected the Nusselt number and pressure drop. As a result, $\mathrm{Al}_{2} \mathrm{O}_{3}$ nanofluid performed better than $\mathrm{CuO}$ nanofluid. Trapezoidal, sinusoidal, and straight counter heat exchangers with water and engine oil were investigated by Khata et al., [12]. Nusselt number was found to be more affected by trapezoidal channels than by sinusoidal and straight channels, respectively. The most straightforward way to determine the applicability of 2D models is to compare 2D and 3D results. Unfortunately, because they used different numerical techniques and considered different boundary parameters, comparing results obtained by previous authors in 2D and 3D models is difficult. It is necessary to verify the results of a comparison by running a series of $2 \mathrm{D}$ and $3 \mathrm{D}$ simulations for the same binary system and boundary conditions using the same numerical technique.

\section{Channel Description}

To analyse the difference between 2D modelling and 3D modelling, this study looks at three different geometries, the first is a non-corrugated model, which has dimensions of length of channel $\mathrm{L}=700 \mathrm{~mm}$, width of the channel $\mathrm{W}=50 \mathrm{~mm}$, and channel hight $\mathrm{H}=10 \mathrm{~mm}$. The second geometry a channel with semi-circular corrugations. The corrugation geometrical properties are represented by corrugation width $(\mathrm{Wc})=5 \mathrm{~mm}$, radius $(r)=2.5 \mathrm{~mm}$, and channel pitch $\left(P_{c h}\right)=21.5 \mathrm{~mm}$. The third channel comprises rectangular corrugations, with a height $(\mathrm{hc})=2.5 \mathrm{~mm}$, width $(\mathrm{Wc})=10 \mathrm{~mm}$, and a pitch $\left(P_{c h}\right)=21.5 \mathrm{~mm}$. Schematic representations of the channels shown in Figure 1 and Figure 2 .

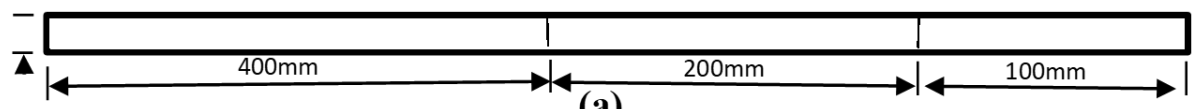

(a)

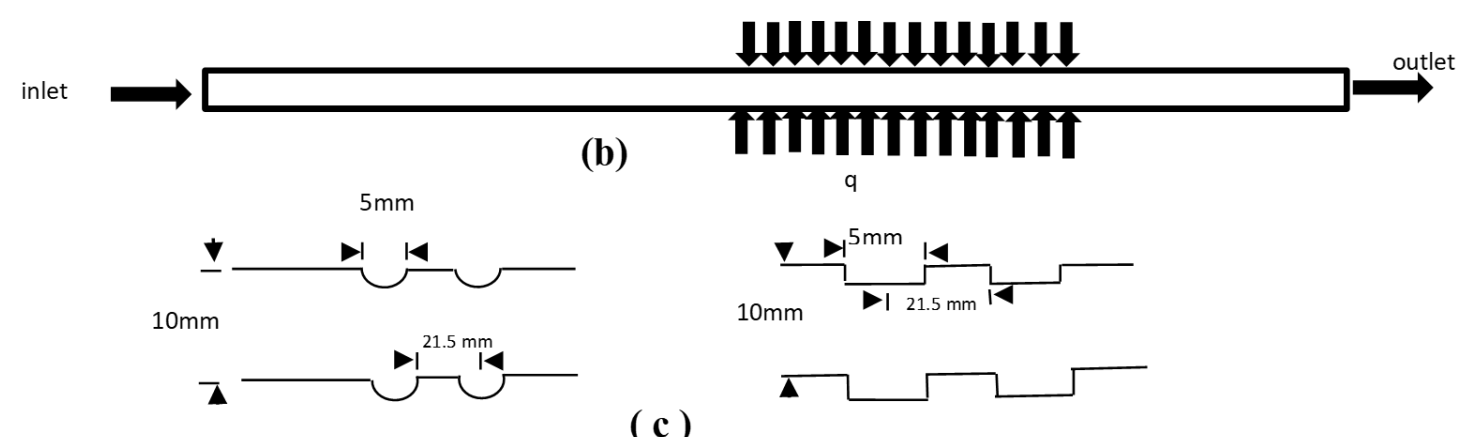

(c)

Fig. 1. Schematic diagram of; (a) computation domain, (b) test section, (c) geometry of semicircle and corrugated channels 


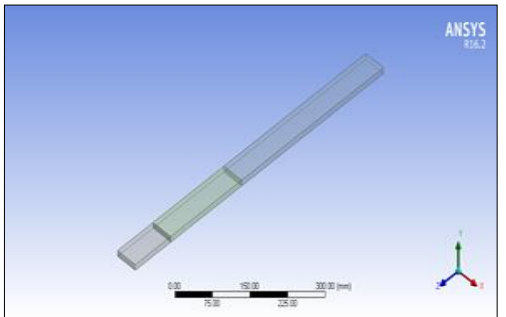

(a)

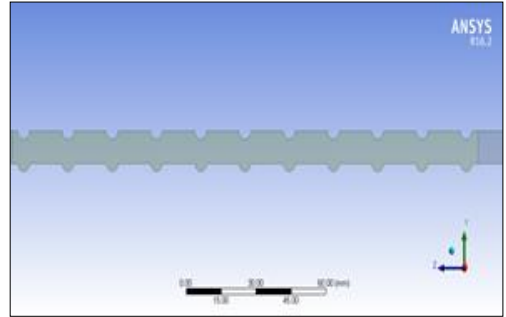

(b)

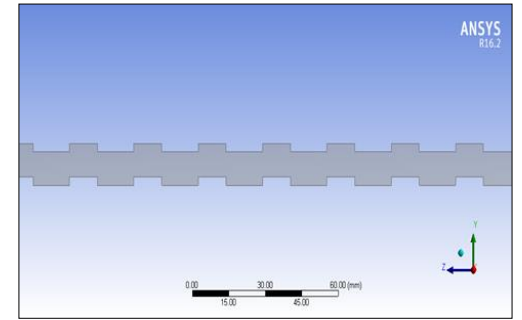

(c)

Fig. 2. Physical domain of the present study; (a) non-corrugated channel, (b) semi-circle-corrugation channel, (c) rectangular-corrugation channel

Corrugations are placed on the top and bottom walls of the channel, with the sides remaining flat. The flow domain is divided into three sections: a test section with corrugations heated from the upper and lower surfaces and an upstream and downstream flat and adiabatic section following an experimental setup [2].

\section{Numerical Setup}

The flow in the domain of interest is assumed to be steady, incompressible, and fully developed. The fluid is single phase, Newtonian and homogeneous. The wall has the surface roughness of stainless steel with constant thermal conductivity. The governing equations for this type of flow are as follows $[13,14,22,23]$ :

Continuity equation:

$\nabla \cdot\left(\rho_{n f} V\right)=0$

Momentum equation:

$\nabla \cdot\left(\rho_{n f} V V\right)=-\nabla P+\nabla \cdot \tau$

Energy equation:

$\nabla \cdot\left(\rho_{n f} V C_{p, n f}\right)=-\nabla \cdot\left(k_{n f} \nabla T-C_{p . n f} \rho_{n f} \overline{\mathrm{v} t}\right)$

Where $\rho_{n f}$ is Density of the nanofluid, $\left(\mathrm{kg} / \mathrm{m}^{2}\right), V$ is dimensionless velocity vector, $\nabla P$ Pressure gradient $(\mathrm{Pa}), \boldsymbol{\tau}$ is wall shear stress $\left(\mathrm{N} / \mathrm{m}^{2}\right), \nabla T$ temperature gradient, $(\mathrm{K}), C_{p, n f}$ is Specific heat of the nanofluid at constant pressure, $(\mathrm{J} / \mathrm{Kg} \mathrm{K})$ and $k_{n f}$ is thermal conductivity of the fluid, $(\mathrm{W} / \mathrm{m} . \mathrm{K})$.

Boundary conditions are applied at the inlet, exit and test sections. These include a velocity inlet condition along with fluid temperature of $300^{\circ} \mathrm{C}$, as well as a pressure outlet condition. The no-slip condition is imposed at the walls. Uniform heat flux $\left(q=10000 \mathrm{~W} / \mathrm{m}^{2}\right)$ are imposed on the corrugated surfaces, whereas the remaining walls are subjected to an adiabatic condition. The following are the specific flow and boundary conditions for the flow and the boundary conditions:

Inlet:

$u=u_{\text {in }}, v=w=0, T_{\text {in }}=300 \mathrm{~K}, k=k_{\text {in }}, \varepsilon=\varepsilon_{\text {in }}$ 
Where $u, v, w$, are velocity components $(\mathrm{m} / \mathrm{s})$ at $\mathrm{x}$-direction, $\mathrm{y}$-direction, $\mathrm{z}$-direction respectively, $\mathrm{k}$ is turbulence kinetic energy and $\varepsilon$ is turbulence dissipation rate.

The properties are assumed to be spatially uniform at the outlet boundary in the current study.

$\frac{\partial T_{f}}{\partial x}=0, \frac{\partial u}{\partial x}=\frac{\partial v}{\partial x}=\frac{\partial w}{\partial x}=0$, and $\frac{\partial k}{\partial x}=\frac{\partial \varepsilon}{\partial x}=0$

Wall:

$u=v=w=0, q=q_{w a l l}$

The turbulent kinetic energy $\left(\mathrm{k}_{\text {in }}\right)$ and turbulent dissipation $\left(\varepsilon_{\text {in }}\right)$ at the inlet are calculated using the turbulent intensity $I$ as follows [15]:

$k_{\text {in }}=\frac{3}{2}\left(u_{i n} I\right)^{2}$

$\varepsilon_{\text {in }}=C_{\mu}^{3 / 4} \frac{k^{3 / 2}}{L}$

where the turbulent intensity $(I)$ is [15]:

$I=0.16 R e^{-8} \%$

The flow is characterized by the Reynolds number (Re), which is defined as:

$R e=\frac{\rho_{n f} u D_{h}}{\mu_{n f}}$

where, $D_{h}$ is the hydraulic diameter of the channel and $\mu_{n f}$ is the dynamic viscosity. The heat transfer capability of the channels is evaluated through the average Nusselt number $\left(N u_{a v}\right)$ defined as follows:

$N u_{a v}=\frac{h_{a v} D_{h}}{k_{n f}}$

where $h_{a v}$ is the mean heat transfer coefficient. The hydraulic diameter in the corrugated section is calculated using the cross-sectional area (Across) and the wetted perimeter $(P)$ as [15]:

$D_{h}=\frac{4 A_{\text {cross }}}{P}$

Thermophysical properties of nanofluid $\left(\mathrm{Water}+\mathrm{SiO}_{2}\right)$ is calculated based on empirical equations from the literature with $\rho=1094\left(\mathrm{~kg} / \mathrm{m}^{3}\right), \mathrm{Cp}=3022(\mathrm{~J} / \mathrm{kg} \mathrm{K}), \mathrm{k}=0.634(\mathrm{~W} / \mathrm{m} \mathrm{K})$ and $\mu=0.004795$ $(\mathrm{kg} / \mathrm{ms})$ [16-19].

The CFD commercial software ANSYS-FLUENT (V16.1) is used to solve the governing equations with corresponding boundary conditions using the finite volume method discretization scheme. The pressure-velocity system coupled using the SIMPLE algorithm, and the convective terms are handled using a 2 nd order upwind scheme. The realizable k-standard wall function turbulent model is chosen, with 2 nd order upwind being used to approximate the diffusion term in the momentum and energy 
equations. For the continuity, momentum, and turbulence equations, residues of $10^{-5}$ are considered converged, while residues of $10^{-8}$ are considered converged for the energy equation.

For validation, the friction factor and average Nusselt number are compared to the empirical correlations of Pethukov et al., [20] and Dittus-Boelter respectively [21] as shown below. Figure 3 shows that the numerical predictions are in good agreement with the empirical correlations:

Pethukov [17]: $\quad f=0.79 \ln (R e)-1.64)^{-2}$

Dittus-Boelter [18]: $\quad N u_{a v}=0.023 \operatorname{Re}^{0.8} \mathrm{Pr}^{0,4}$

Where $f$ is friction factor and $P_{r}$ is Prandtl No.

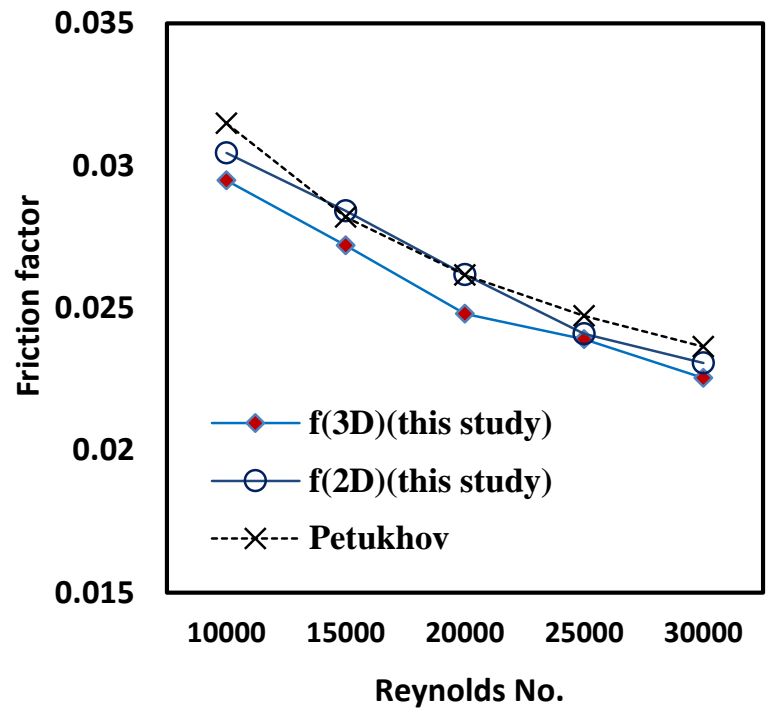

(a)

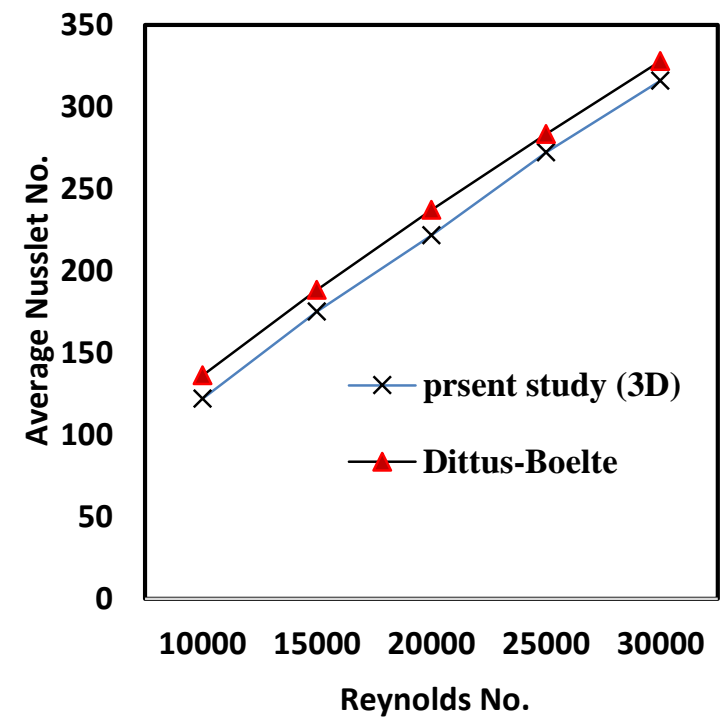

(b)

Fig. 3. Comparison of (a) friction factor (b) Average Nusselt No. with the empirical correlations

\section{Results and Discussion}

The study compares the prediction of pressure drop and heat transfer characteristics of flow in corrugated channels with 3D and 2D numerical approaches. Figure 4 compares the Nu predictions for different types of corrugations with 2D and 3D numerical setups. Nu is seen to increase with $\operatorname{Re}$ for all cases. This is expected since higher Re results in stronger mixing of the fluids, hence the higher energy transfer. It can be observed that there is good agreement between the Nu predictions for smooth (non-corrugated) channels with less than approximately $5 \%$ maximum difference. The predictions for semi-circular corrugated channel show good agreement between 2D and 3D predictions at Re up to 20000. Beyond this range of Re, a larger difference (appr. 17\%) can be seen. Figure 5 and Figure 6 show the temperature and velocity contoursfor $2 D$ and 3D $(x=0.025$ at the middle) at $\mathrm{Re}=25000$ respectively, it can be seen clearly the difference between the two models, the temperature counters show that the max temperature for 2D model is $301.7 \mathrm{k}$ while the maximum temperature which detected by 3D model is $302.259 \mathrm{k}$, from this it can be said that 3D model more capable or more cocurate for high Reynolds Number. Moreover, velocity contours illustrate that 3D model is more resolution than 2D model and can mounter in-depth details. For rectangular corrugation, the prediction of $\mathrm{Nu}$ by 2D and 3D models are almost similar withing less than $7 \%$ difference with 2D prediction lower Nusselt numbers. 


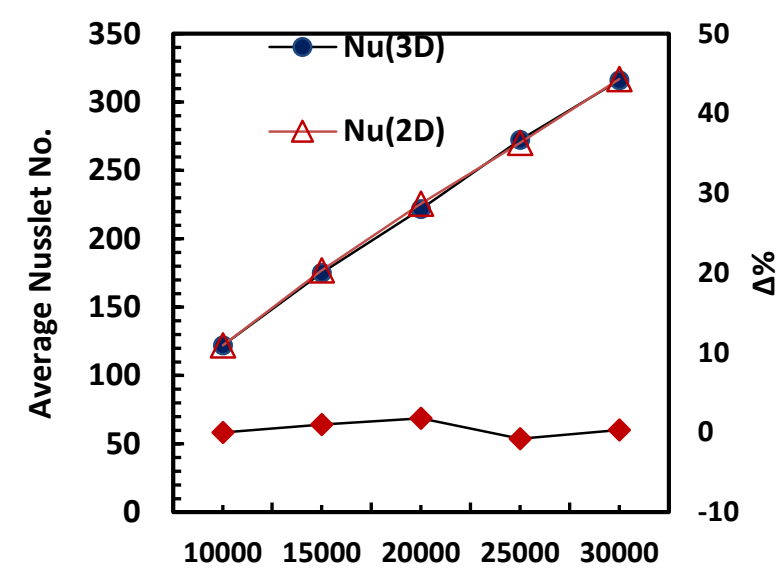

Reynolds No.

(a)

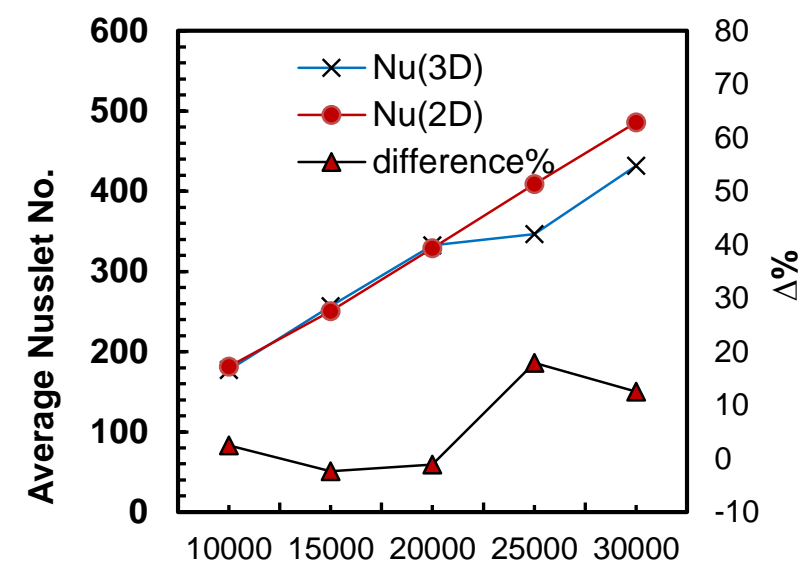

Reynolds No.

(b)

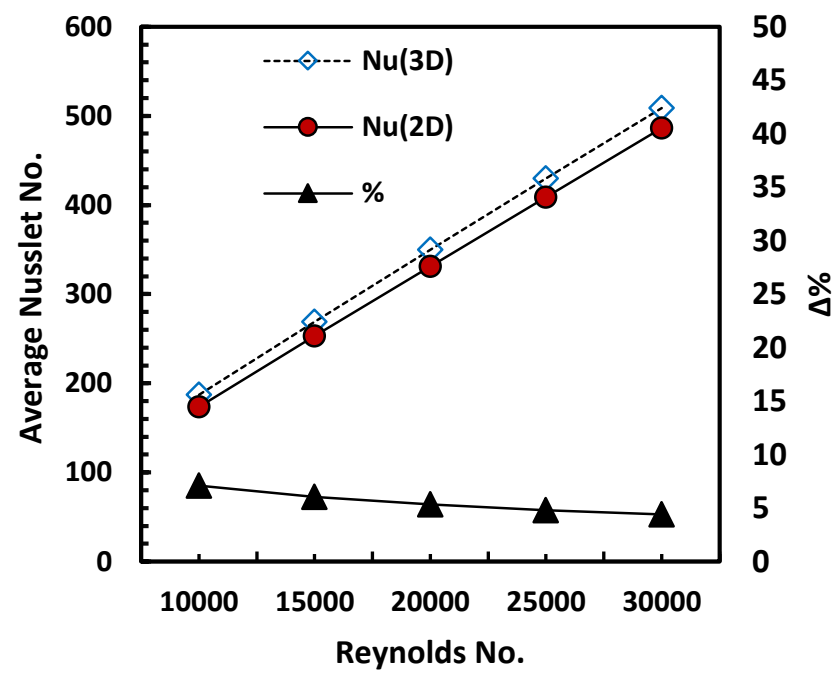

(c)

Fig. 4. Nusselt No. vs Reynold's No. (a) non-corrugated (b) semi-circle-corrugation (c) rectangularcorrugation

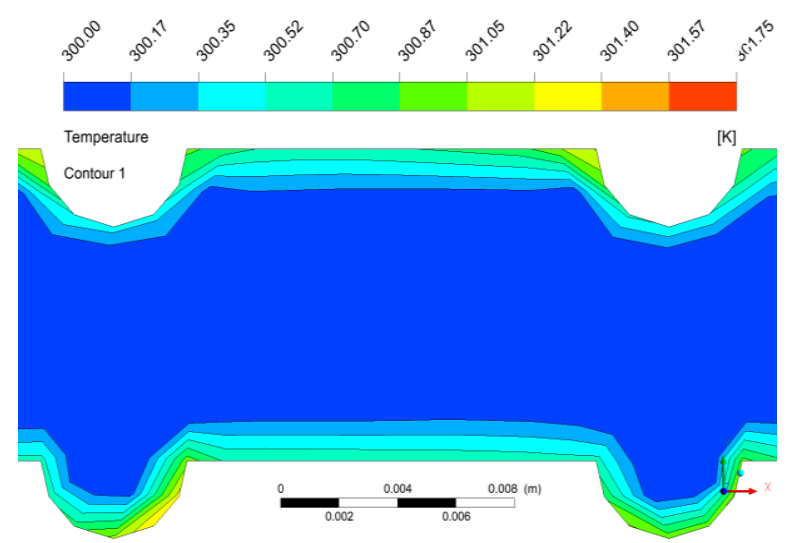

(a)

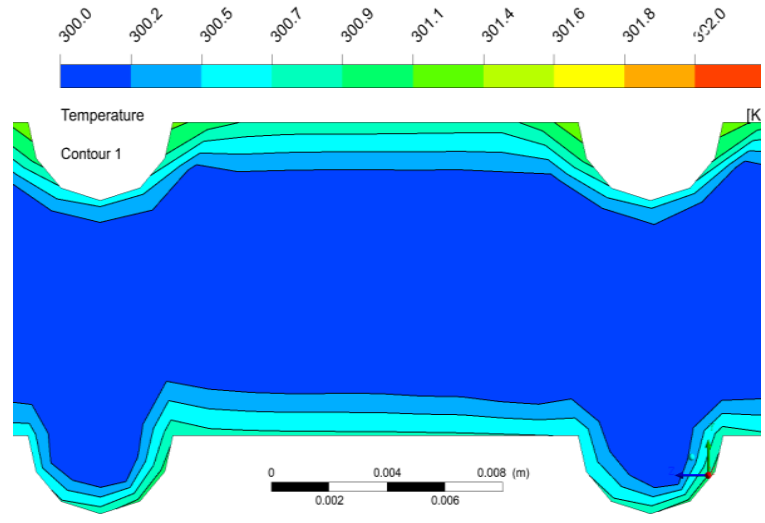

(b)

Fig. 5. Temperature contours for (a) $2 \mathrm{D}$ and (b) $3 \mathrm{D}$ at $\mathrm{x}=0.025 \mathrm{~mm}$ (middle plane), models at $\mathrm{Re}=$ 25000 


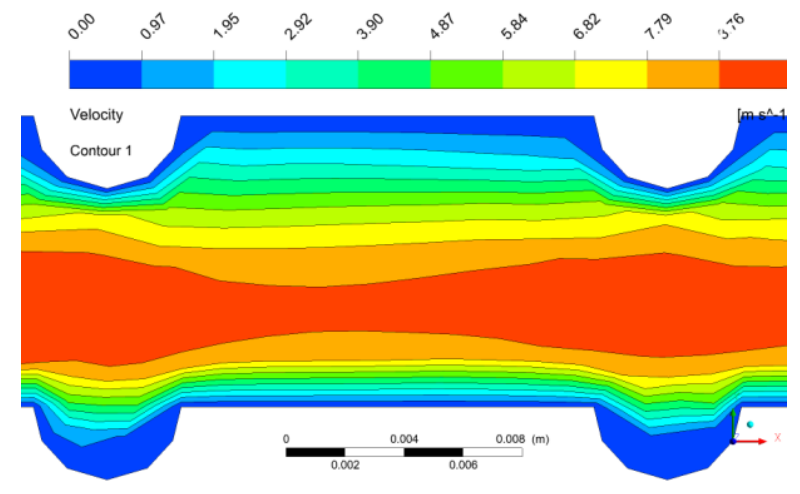

(a)

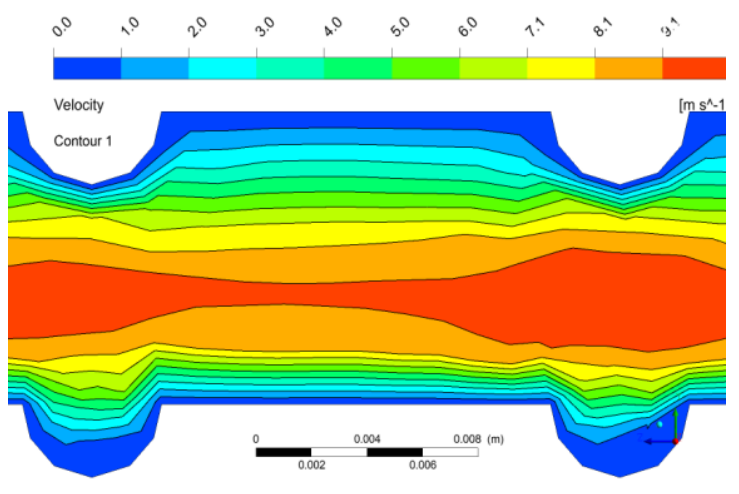

(b)

Fig. 6. Velocity contours for (a) $2 \mathrm{D}$ and (b) $3 \mathrm{D}$ at $\mathrm{x}=0.025 \mathrm{~mm}$ (middle plane), models at $\mathrm{Re}=$ 25000

Figure 7 displays the predicted pressure drop $(\Delta P)$ along the length of the channels for three different corrugation geometries. It can be noticed that the predictions using 2D and 3D approaches show similar trends in that $\Delta \mathrm{P}$ increases with the increase in Re. For non-corrugated channel, the $2 \mathrm{D}$ simulation predicts lower $\triangle \mathrm{P}$ compared to $3 \mathrm{D}$ simulations. The differences are less noticeable for corrugated surfaces. The $2 \mathrm{D}$ model predicts higher $\Delta \mathrm{P}$ at $\mathrm{Re}=25000$ resulting in a $18 \%$ difference with the 3D prediction. In the case of rectangular corrugations, the two models are seen to be within $10 \%$ agreement with each other with the $2 \mathrm{D}$ model predicting slightly lower $\Delta \mathrm{P}$ over the range of Re. Figure 8 shows pressure contours for 2Dand 3D (center plane) models at $R e=25000$, it can be noted that 3D mode gives more details and clearly displays several different pressure regions.

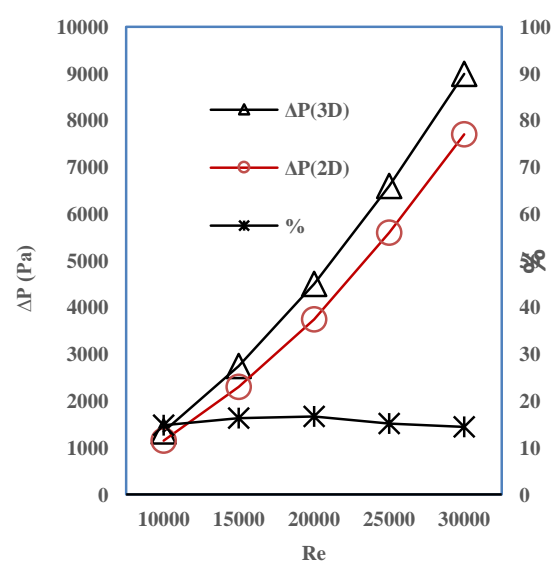

(a)

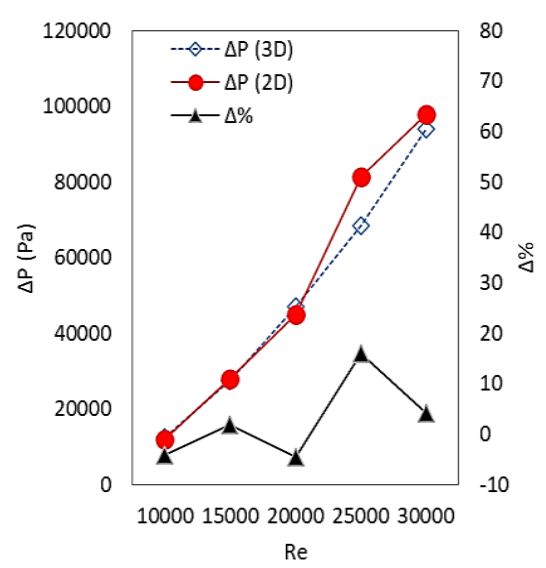

(b)

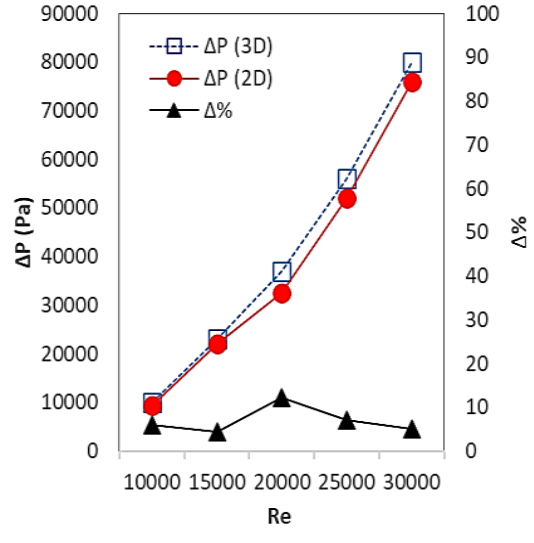

(c)

Fig. 7. Pressure drops vs Reynold's no. (a) non-corrugated (b) semi-circle corrugation (c) rectangularcorrugation 


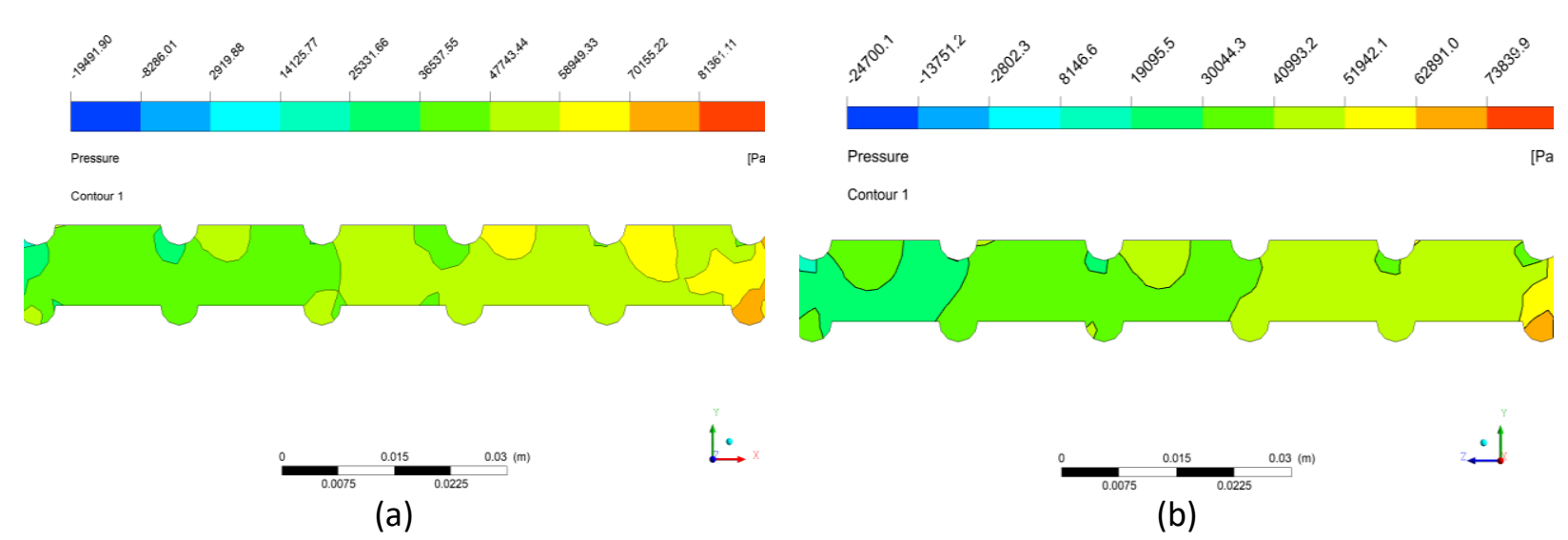

Fig. 8. Pressure contour for (a) $2 \mathrm{D}$ and (b) $3 \mathrm{D}$ at $\mathrm{x}=0.025 \mathrm{~mm}$ (middle plane), models at $\mathrm{Re}=25000$

Figure 9 shows the velocity contours for 2D and (3D at 3 different longitudinal planes $x=0.001, x$ $=0.025, x=0.049$ ) for semicircle-corrugation for Reynold's No. $=10000$, it can be noted that the max velocity occurs at the middle plane and it decreases as the flow becomes near the wall and that because of the fully developed flow, moreover 2D contour is almost similar to the middle plane of 3D model at $x=0.025$. The same behaviour for rectangular corrugation which is illustrated by Figure 10 .
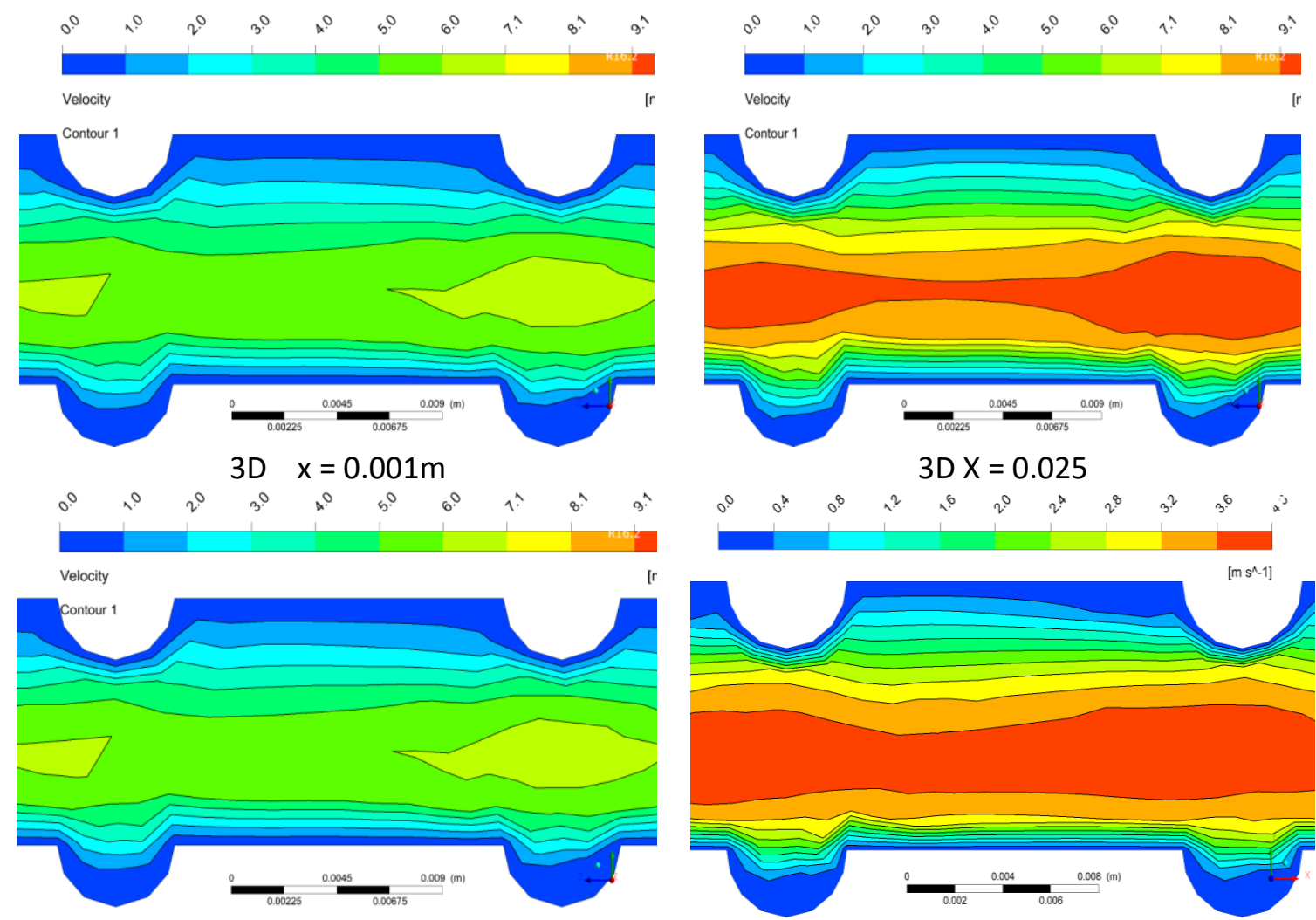

3D $x=0.049$

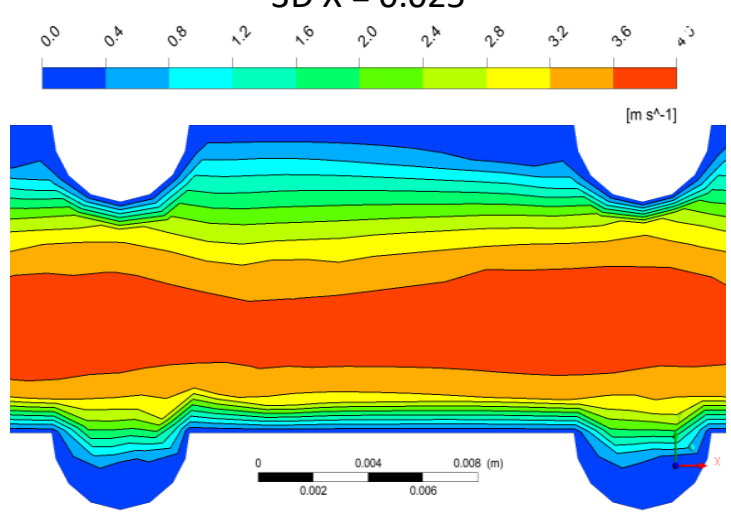

Fig. 9. Velocity contour for semi-circle channel at $\mathrm{Re}=10000$ 


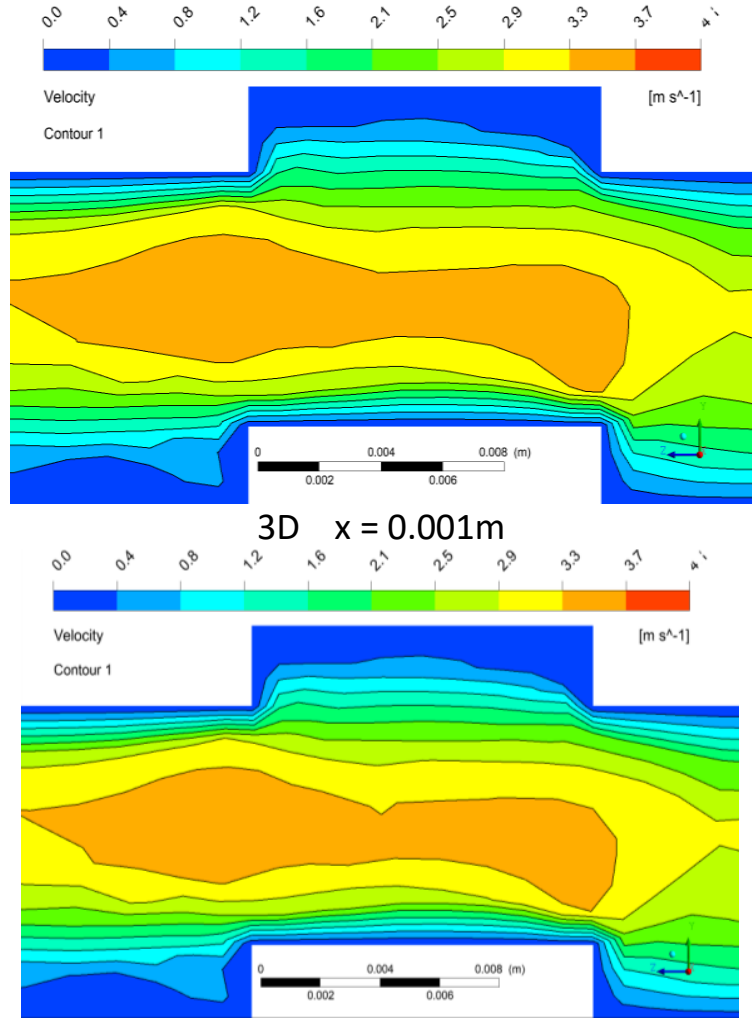

3D $x=0.049$

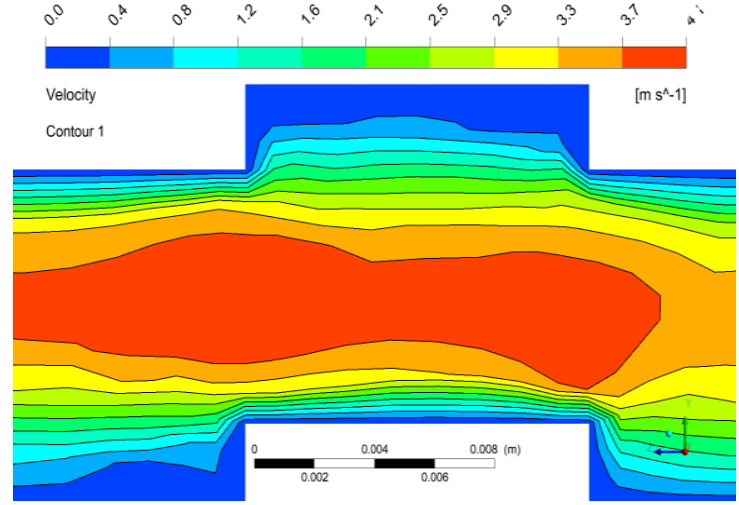

$3 D X=0.025$

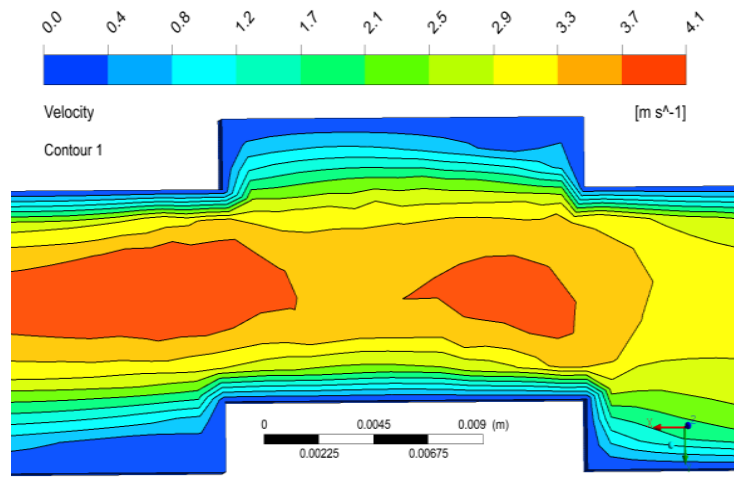

$2 \mathrm{D}$

Fig. 10. velocity contour for rectangular channel at $\mathrm{Re}=10000$

From the results above we can note the following: For all types 2D modelling shows results for only one plane which is similar to the mid plane of the 3D. The other planes if we go closer to the wall 2D modelling unable to give any information about it. Also, for lateral cross-sections cannot be visualized by $2 \mathrm{D}$ modelling. The results were not significantly different for, the two-dimensional However, when using a three-dimensional turbulence model, slightly different results were obtained that were qualitatively closer to those obtained experimentally, possibly justifying the use of a threedimensional approach when precision is required. When simulating fluids with CFD tools on a 2D/planar mesh and a 3D/volume mesh, the flow will obviously differ depending on the cross-section. If the cross-section of each channel is rectangle, a planar mesh solution gives similar results to a 3D mesh in a flow mixing simulation, whereas if the channel is of any other cross-section, the flow physics will vary. Aside from the geometry, the difference between 2D and 3D is determined by several factors. The first thing that comes to mind is turbulence. Mixing and, more broadly, diffusion is never purely 2D phenomena. When using Reynold's averaged Navier Stocks RANS models and turbulent conditions, 3D diffusion may be accounted for by the turbulence transport equation quantities. If the conditions are laminar, everything is dependent on the geometry.

\section{Conclusions}

A comparison between 2D and 3D modelling for the turbulent forced convection flow of nanofluid through different shapes of corrugation (semi-circle and rectangular) besides to non-corrugated channels was implemented numerically to investigate the difference between both two models. Ansys fluent software was used to study the effect of suspension of nano particles of $\mathrm{SiO}_{2}$ into water as a base fluid and to determine to what extent 2D modelling is sufficient to display the behaviour of thermohydraulic characteristics of the convective heat transfer flow through the channels. 2D and 
3D simulations were conducted for Reynold's numbers range from 10000 to 30000 . The results show the following:

i. For non-corrugated channel, the variation of average Nusselt's No. with Reynold's No. is almost the same for both 2D and 3D for all Reynold's Numbers and this can be said for pressure drop.

ii. For semi-circle and rectangular corrugated channels, the difference between 2D and 3D simulation for the two studied parameters, increased at high Reynolds number.

iii. $\mathrm{Nu}$ is seen to increase with Re for all cases, there is good agreement between the $\mathrm{Nu}$ predictions for smooth (non-corrugated) channels with less than approximately $5 \%$ maximum difference. The predictions for semi-circular-corrugation channel show good agreement between 2D and 3D predictions at Re up to 20000. Beyond this range of $\mathrm{Re}, \mathrm{a}$ larger difference (appr. 17\%) can be seen. For rectangular corrugation, the prediction of $\mathrm{Nu}$ by $2 \mathrm{D}$ and $3 \mathrm{D}$ models are almost similar withing less than $7 \%$ difference with 2D prediction lower Nusselt numbers.

iv. For semi-circle corrugation channel. The $2 \mathrm{D}$ model predicts higher $\Delta \mathrm{P}$ at $\mathrm{Re}=25000$ resulting in a $18 \%$ difference with the $3 \mathrm{D}$ prediction.

v. Visualization of velocity, temperature, pressure contours show that the $2 \mathrm{D}$ simulation can display only one plane which is similar to the middle plane that of 3D simulation while for other longitudinal planes the 2D simulation unable to give any information.

\section{Acknowledgement}

The authors would like to thank the Ministry of Higher Education Malaysia for supporting this research under Fundamental Research Grant Scheme Vot No. FRGS/1/2019/SKK15/UTHM/02/1and partially sponsored by Universiti Tun Hussein Onn Malaysia.

\section{References}

[1] Ajeel, Raheem K., Wan S. W. Salim, and Khalid Hasnan. "Numerical investigations of flow and heat transfer enhancement in a semicircle zigzag corrugated channel using nanofluids." International Journal of Heat and Technology 36, no. 4 (2018): 1292-1303. https://doi.org/10.18280/ijht.360418

[2] Ajeel, Raheem K., W. S-I. W. Salim, and Khalid Hasnan. "Experimental and numerical investigations of convection heat transfer in corrugated channels using alumina nanofluid under a turbulent flow regime." Chemical Engineering Research and Design 148 (2019): 202-217. https://doi.org/10.1016/i.cherd.2019.06.003

[3] Ajeel, Raheem Kadhim, Wan Saiful-Islam Wan Salim, and Khalid Hasnan. "Impacts of corrugation profiles on the flow and heat transfer characteristics in trapezoidal corrugated channel using nanofluids." Journal of Advanced Research in Fluid Mechanics and Thermal Sciences 49, no. 2 (2018): 170-179.

[4] Rostamani, M., S. F. Hosseinizadeh, M. Gorji, and J. M. Khodadadi. "Numerical study of turbulent forced convection flow of nanofluids in a long horizontal duct considering variable properties." International Communications in Heat and Mass Transfer 37, no. 10 (2010): 1426-1431. https://doi.org/10.1016/i.icheatmasstransfer.2010.08.007

[5] Krishnappa, G. B., D. Madhu, and Srinivasan Kasthurirengan. "Comparison of 1D and 2D flow numerical analysis applied to two stage pulse tube cryocooler." In AIP Conference Proceedings, vol. 1434, no. 1, pp. 1157-1164. American Institute of Physics, 2012. https://doi.org/10.1063/1.4707037

[6] Santra, Apurba Kumar, Swarnendu Sen, and Niladri Chakraborty. "Study of heat transfer due to laminar flow of copper-water nanofluid through two isothermally heated parallel plates." International Journal of Thermal Sciences 48, no. 2 (2009): 391-400. https://doi.org/10.1016/j.ijthermalsci.2008.10.004

[7] Li, J., G. P. Peterson, and P. Cheng. "Three-dimensional analysis of heat transfer in a micro-heat sink with single phase flow." International Journal of Heat and Mass Transfer 47, no. 19-20 (2004): 4215-4231. https://doi.org/10.1016/i.ijheatmasstransfer.2004.04.018

[8] Manca, Oronzio, Sergio Nardini, and Daniele Ricci. "A numerical study of nanofluid forced convection in ribbed $\begin{array}{llllll}\text { channels." } & \text { Applied } & \text { Thermal } & \text { Engineering } & 37 & \text { (2012): }\end{array}$ https://doi.org/10.1016/j.applthermaleng.2011.11.030 
[9] Ahmed, M. A., N. H. Shuaib, Mohd Zamri Yusoff, and A. H. Al-Falahi. "Numerical investigations of flow and heat transfer enhancement in a corrugated channel using nanofluid." International Communications in Heat and Mass Transfer 38, no. 10 (2011): 1368-1375. https://doi.org/10.1016/i.icheatmasstransfer.2011.08.013

[10] Al-Shamani, Ali Najah, K. Sopian, H. A. Mohammed, Sohif Mat, Mohd Hafidz Ruslan, and Azher M. Abed. "Enhancement heat transfer characteristics in the channel with Trapezoidal rib-groove using nanofluids." Case Studies in Thermal Engineering 5 (2015): 48-58. https://doi.org/10.1016/i.csite.2014.12.003

[11] Kriby, Saliha, Mohamed Announ, and Tayeb Kermezli. "2D CFD simulation to investigate the thermal and hydrodynamic behavior of nanofluid flowing through a pipe in turbulent conditions." CFD Letters 11, no. 11 (2019): 58-75.

[12] Khata, Naseer Dawood, Zena Khalefa Kadim, and Kamil Abdulhussein Khalaf. "Numerical Study of Heat Transfer Enhancement in Contour Corrugated Channel Using Water and Engine Oil." CFD Letters 12, no. 12 (2020): 17-37. https://doi.org/10.37934/cfdl.12.12.1737

[13] Schlichting, Herrmann, and Klaus Gersten. Boundary-layer theory. Springer Science \& Business Media, 2000. https://doi.org/10.1007/978-3-642-85829-1

[14] Abobaker, Mostafa, Abdulhafid M. Elfaghi, and Sogair Addeep. "Numerical Study of Wind-Tunnel Wall Effects on Lift and Drag Characteristics of NACA 0012 Airfoil." CFD Letters 12, no. 11 (2020): 72-82. https://doi.org/10.37934/cfdl.12.11.7282

[15] Mohammed, H. A., Azher M. Abed, and M. A. Wahid. "The effects of geometrical parameters of a corrugated channel with in out-of-phase arrangement." International Communications in Heat and Mass Transfer 40 (2013): 47-57. https://doi.org/10.1016/i.icheatmasstransfer.2012.10.022

[16] Pak, Bock Choon, and Young I. Cho. "Hydrodynamic and heat transfer study of dispersed fluids with submicron metallic oxide particles." Experimental Heat Transfer an International Journal 11, no. 2 (1998): $151-170$. https://doi.org/10.1080/08916159808946559

[17] Corcione, Massimo. "Empirical correlating equations for predicting the effective thermal conductivity and dynamic viscosity of nanofluids." Energy Conversion and Management 52, no. 1 (2011): $789-793$. https://doi.org/10.1016/i.enconman.2010.06.072

[18] Vajjha, Ravikanth S., and Debendra K. Das. "A review and analysis on influence of temperature and concentration of nanofluids on thermophysical properties, heat transfer and pumping power." International Journal of Heat and Mass Transfer 55, no. 15-16 (2012): 4063-4078. https://doi.org/10.1016/j.ijheatmasstransfer.2012.03.048

[19] Xuan, Yimin, and Wilfried Roetzel. "Conceptions for heat transfer correlation of nanofluids." International Journal of Heat and Mass Transfer 43, no. 19 (2000): 3701-3707. https://doi.org/10.1016/S0017-9310(99)00369-5

[20] Petukhov, B. S. "Heat transfer and friction in turbulent pipe flow with variable physical properties." In Advances in Heat Transfer, vol. 6, pp. 503-564. Elsevier, 1970. https://doi.org/10.1016/S0065-2717(08)70153-9

[21] Dittus, F. W., and L. M. K. Boelter. "Heat transfer in automobile radiators of the tubular type." International Communications in Heat and Mass Transfer 12, no. 1 (1985): 3-22. https://doi.org/10.1016/0735-1933(85)90003$\underline{x}$

[22] Alarami, Abolgasem Mesoad, and Abdulhafid M. Elfaghi. "Optimum design procedures of turbojet combustion chamber." In 2nd Intl'Conference on Advances in Engineering Sciences and Applied Mathematics (ICAESAM'2014), pp. 4-5. 2014.

[23] Ennil, Ali S. Bahr, and Abdulhafid M. Elfaghi. "Numerical simulation of film cooling over flat plate." New Approaches in Engineering Research 12 (2021): 10-16. https://doi.org/10.9734/bpi/naer/v12/8210D 